\title{
Development and Validation of a Simple High Performance Liquid Chromatography/UV Method for Simultaneous Determination of Urinary Uric Acid, Hypoxanthine, and Creatinine in Human Urine
}

\author{
Nimanthi Wijemanne, ${ }^{1}$ Preethi Soysa $\left(\mathbb{D},{ }^{1}\right.$ \\ Sulochana Wijesundara, ${ }^{1}$ and Hemamali Perera $\mathbb{D}^{2}$ \\ ${ }^{1}$ Department Biochemistry and Molecular Biology, Faculty of Medicine, University of Colombo, Colombo, Sri Lanka \\ ${ }^{2}$ Department of Psychological Medicine, Faculty of Medicine, University of Colombo, Colombo, Sri Lanka
}

Correspondence should be addressed to Preethi Soysa; indunilsree@gmail.com

Received 5 December 2017; Revised 3 February 2018; Accepted 8 February 2018; Published 15 May 2018

Academic Editor: David M. Lubman

Copyright (C) 2018 Nimanthi Wijemanne et al. This is an open access article distributed under the Creative Commons Attribution License, which permits unrestricted use, distribution, and reproduction in any medium, provided the original work is properly cited.

\begin{abstract}
Uric acid and hypoxanthine are produced in the catabolism of purine. Abnormal urinary levels of these products are associated with many diseases and therefore it is necessary to have a simple and rapid method to detect them. Hence, we report a simple reverse phase high performance liquid chromatography (HPLC/UV) technique, developed and validated for simultaneous analysis of uric acid, hypoxanthine, and creatinine in human urine. Urine was diluted appropriately and eluted with C-18 column $100 \mathrm{~mm} \times 4.6 \mathrm{~mm}$ with a C-18 precolumn $25 \mathrm{~mm} \times 4.6 \mathrm{~mm}$ in series. Potassium phosphate buffer $(20 \mathrm{mM}$, pH 7.25$)$ at a flow rate of $0.40 \mathrm{~mL} / \mathrm{min}$ was employed as the solvent and peaks were detected at $235 \mathrm{~nm}$. Tyrosine was used as the internal standard. The experimental conditions offered a good separation of analytes without interference of endogenous substances. The calibration curves were linear for all test compounds with a regression coefficient, $r^{2}>0.99$. Uric acid, creatinine, tyrosine, and hypoxanthine were eluted at 5.2, 6.1, 7.2, and $8.3 \mathrm{~min}$, respectively. Intraday and interday variability were less than $4.6 \%$ for all the analytes investigated and the recovery ranged from 98 to 102\%. The proposed HPLC procedure is a simple, rapid, and low cost method with high accuracy with minimum use of organic solvents. This method was successfully applied for the determination of creatinine, hypoxanthine, and uric acid in human urine.
\end{abstract}

\section{Introduction}

In purine catabolism, xanthine oxidase oxidizes hypoxanthine to xanthine and then xanthine to uric acid. The balance between the uric acid synthesis and degradation maintains uric acid levels in serum. The abnormal levels of uric acid in serum and urine are associated with defects in enzymes in purine metabolism $[1,2]$ and are reported in cardiovascular diseases, gouty arthritis, renal disease, type 2 diabetes, obesity, and hypertension [2-8].

The total daily excretion of creatinine at steady state is considered to be proportional to the total-body creatinine content and total-body skeletal muscle mass [9]. Therefore the levels of creatinine have been used to standardize the concentration of urinary constituents to improve the accuracy of the analysis [10-12]. In most studies colorimetric methods are used to determine urinary creatinine levels [13]. Employing a simultaneous analysis of purine metabolites together with creatinine is a better approach to improve the accuracy of the measurements and also it reduces the time, labour, and cost per sample. HPLC methods for simultaneous quantification of creatinine, uric acid, and hypoxanthine have been reported. Analysis of creatinine and purine derivatives in ruminant urine has been described using HPLC with gradient or isocratic solvent systems [14-16]. HPLC analysis of uric acid and hypoxanthine in human urine has also been 
reported [13]. A more complex method with liquid chromatographic system equipped with automatic column-switching valves has been used to analyse creatinine, hypoxanthine, and uric acid [17].

The present method employs a further improvement of our previous study [18]. An internal standard was used to improve the accuracy in the quantification of analytes. The method developed was applied to determine urinary creatinine, uric acid, and hypoxanthine levels in children with autism.

\section{Instrumentation}

HPLC was performed with Shimadzu LC10AS solvent delivery system equipped with Shimadzu SPD-10AVP UV visible detector, DGU-14A degaser (Shimadzu, Kyoto, Japan), chromolith RP-18e 25-4.6 mm column (the precolumn) coupled in series with chromolith flash, and RP 18 e 100-4.6 mm column. Microcentrifugation of samples was carried out in Biofuge D-37520 (Heraeus instruments) centrifuge. Samples were injected with a syringe loading injector fitted with $20 \mu \mathrm{L}$ loop.

\section{Reagents}

Acetonitrile (HPLC grade), sodium acetate, and tyrosine were purchased from BDH (BDH Chemicals Limited, Poole, England). Dipotassium hydrogen orthophosphate, potassium dihydrogen phosphate, creatinine, uric acid, hypoxanthine, and sodium hydroxide were purchased from Riedel-de Haen AG, Seelze, Hannover. Deionized water to prepare the standards and the mobile system were obtained from Milli Q50 water purification system (Millipore, USA).

\section{Collection of Urine}

Six samples of human urine were analyzed for creatinine, uric acid, and hypoxanthine as an application of the method. Urine was collected to sterile plastic bottles. The total volume was measured. Aliquots $(2 \mathrm{~mL}$ in duplicate and $10 \mathrm{~mL}$ ) were centrifuged at $2500 \mathrm{rpm}$ for $5 \mathrm{~min}$ and the supernatant was transferred to autoclaved sterile tubes. The lids were covered with parafilm, and samples were stored at $-20^{\circ} \mathrm{C}$ until analyzed. The sample analysis was done within 24 hours of collection.

\section{Preparation of Mobile Phase}

The mobile phase, potassium phosphate buffer $(20 \mathrm{mM}, \mathrm{pH}$ 7.25), was prepared by mixing $\mathrm{K}_{2} \mathrm{HPO}_{4}(240 \mathrm{~mL} ; 20 \mathrm{mM})$ with $\mathrm{KH}_{2} \mathrm{PO}_{4}(60 \mathrm{~mL} ; 20 \mathrm{mM})$.

\section{Preparation of Standards}

The stock standards were prepared at a concentration of $500 \mu \mathrm{g} / \mathrm{mL}$ for each analyte, uric acid, creatinine, and hypoxanthine in $100 \mathrm{~mL}$ volumetric flasks with deionized water or urine. Few drops of $\mathrm{NaOH}(0.5 \mathrm{M})$ were added to dissolve hypoxanthine and uric acid. The standards were stored at $-20^{\circ} \mathrm{C}$. Calibration standards consisting of uric acid, creatinine, and hypoxanthine were prepared by appropriate dilutions of the stock standards with deionized water. Tyrosine $(250 \mu \mathrm{g} / \mathrm{mL})$ dissolved in acetonitrile $(100 \%)$ was used as the internal standard.

\section{Sample Preparation for HPLC Analysis}

Chromatographic separation was achieved by coupling RP18e 25-4.6 mm column (precolumn) with RP 18e 100-4.6 mm column. Internal standard, tyrosine $(100 \mu \mathrm{L})$, was added to each standard mixture or urine $(100 \mu \mathrm{L})$ and vortex mixed for 30 seconds followed by centrifugation ( $5 \mathrm{~min}$ at $3000 \mathrm{rpm}$ ); the supernatant $(20 \mu \mathrm{L})$ was injected.

\section{Chromatographic Conditions}

The optimum separation was achieved by potassium phosphate buffer $(20 \mathrm{mM}, \mathrm{pH} 7.25)$ at a flow rate of $0.40 \mathrm{~mL} / \mathrm{min}$. Effluents were monitored at different UV wave lengths and optimum sensitivity was detected at $235 \mathrm{~nm}$ for purine metabolites, creatinine, and the internal standard. Interference of tyrosine was not observed with retention times of analytes or endogenous substances present in urine.

The mobile phase was pumped for $30 \mathrm{~min}$ time period through the column before the commencement of analysis. Column was flushed with degassed, deionized water for $20 \mathrm{~min}$ and then with $8 \%$ acetonitrile for $20 \mathrm{~min}$ after analysis of samples. The columns were left with $8 \%$ acetonitrile until the next usage to protect them from microbes.

\section{Method Validation}

The method was validated according to the US-FDA Bioanalytical Method Validation Guidance to evaluate selectivity, linearity, lower limit of quantification (LLOQ), precision and accuracy, recovery, and stability.

Quality control (QC) samples were prepared at concentrations of $12.5,25.0$, and $75.0 \mu \mathrm{g} / \mathrm{mL}$ for each analyte using deionized water and stored at $-20^{\circ} \mathrm{C}$. QC samples were used for method validation and sample analysis to ensure the quality of data.

Limit of Detection (LOD) and Limit of Quantification (LOQ) were analyzed based on the standard deviation (SD) of the response and the slope. Five calibration curves were constructed for each analyte in the concentration range of $3.13-25.0 \mu \mathrm{g} / \mathrm{mL}$. The SD obtained at each concentration was plotted against the concentration. The intercept at zero concentration $\left(\mathrm{SD}_{0}\right)$ obtained by extrapolation of the curve was used to evaluate the LOD and LOQ. The LOD was calculated as the $3 * \mathrm{SD}_{0}$ and LOQ was $10 * \mathrm{SD}_{0}$ [19]. The lower limit of quantitation (LLOQ) was determined from the lowest concentration of the standard curve with an acceptable accuracy and precision in analysis.

The standards were diluted in water to obtain different concentrations of uric acid $(3.12-200 \mu \mathrm{g} / \mathrm{mL})$, creatinine $(3.12-100 \mu \mathrm{g} / \mathrm{mL})$, and hypoxanthine $(6.25-200 \mu \mathrm{g} / \mathrm{mL})$ and used to determine the linearity of the calibration curve. 
Matrix effects were also studied after diluting the standards with urine.

The calibration curve was obtained with concentration against corresponding peak area ratio. The slope and intercept of the calibration curves were calculated through least squares linear regression analysis using Microsoft Excel 2013. The slope and the intercept of the calibration curves were obtained over a period of 6 weeks using eight independent series of the calibration standards prepared as described above.

The samples were stored at $-20^{\circ} \mathrm{C}$. Three concentrations $(12.5,25$, and $75 \mu \mathrm{g} / \mathrm{mL})$ with three freeze thaw cycles over six weeks were evaluated for stability. The observed values were compared with the freshly made relevant standards.

\section{Application of the Proposed Method}

Urine samples of six autism patients were analyzed as an application of the developed method. The dilutions of urine were prepared by observing the initial HPLC chromatogram in quantification of purine metabolites and creatinine and $20 x$ and 40x dilutions were made accordingly depending on their concentrations. Dilutions at $4 x$ dilutions were made in the analysis of hypoxanthine in urine. Calibration curves were constructed simultaneously in sample analysis to calculate the urinary levels of uric acid creatinine and hypoxanthine.

\section{Results and Discussion}

11.1. Optimization of Chromatographic Separation. Different approaches have been published for simultaneous determination of uric acid, hypoxanthine, and creatinine [12-18, 20]. The method described in the present study employs a precolumn in series for better resolution of analytes and the internal standard at a shorter period of run time for a single injection.

The mobile phase composition was optimized to separate all the analytes as well as the internal standard without interfering coeluting endogenous substance following injection of blank urine samples. Several modifications of the composition of the mobile phase were carried out to find out a best resolution. The detection UV wave length for effluents was also studied to obtain the maximum sensitivity to quantify the analytes simultaneously. Effects of $\mathrm{pH}$ (3 to 7.25), flow rate, and the molarity of the running buffer were optimized using standards and human urine samples to improve the precision and accuracy. Uric acid ( $\mathrm{pKa}$ value 5.4) showed fluctuations of retention time with the $\mathrm{pH}$ compared to creatinine and hypoxanthine. Optimum chromatographic conditions for the simultaneous analysis of uric acid, creatinine, and hypoxanthine were obtained with potassium phosphate buffer $(20 \mathrm{mM}, \mathrm{pH} 7.25)$ at a flow rate of $0.4 \mathrm{~mL} / \mathrm{min}$ with a detection wave length of $235 \mathrm{~nm}$. All the experiments were carried out at room temperature.

The column was washed with deionized water daily to avoid the risk of precipitating salts in the column and kept in $8 \%$ acetonitrile to prevent fungal and bacterial attacks due to the usage of buffers. The daily washing and storing process with acetonitrile also prevented the aggregation of the bonded hydrocarbon chains which may occur due to the usage of aqueous mobile phases [20].

\section{Validation of the HPLC Assay}

The developed HPLC assay was validated for linearity, specificity, stability, accuracy, precision, and repeatability. The limit of detection (LOD) and limit of quantification (LOQ) were also determined.

\section{Selectivity and Specificity}

The samples were initially run for 45 mins to screen any endogenous substances, which might affect the next sample injection. Chromatograms of blank urine samples were examined and the method was optimized to avoid the interference from the analyte peaks with endogenous peaks of the urine and the internal standard. No endogenous interfering peaks were observed in the individual blank sample at the retention time (RT) of the three analytes and the internal standard. Although the peaks appeared broad due to passage through two columns, excellent chromatographic separation was obtained with RT of 5.2, 6.0, 7.1, and 8.2 mins for uric acid, creatinine, Internal standard (tyrosine), and hypoxanthine, respectively. Figure 1 illustrates representative chromatograms of a mixture of standards in water and urine spiked with the internal standard under the described chromatographic conditions.

\section{Linearity}

Intraday ( $n=5$ ) was established by constructing calibration curves for standards of uric acid (3.12-200 $\mu \mathrm{g} / \mathrm{mL})$, hypoxanthine $(6.25-200 \mu \mathrm{g} / \mathrm{mL})$, and creatinine $(3.12-100 \mu \mathrm{g} / \mathrm{mL})$ in water. The ratio of the peak area of the standards to that of the internal standard against the concentration in aqueous solutions was linear (Figure 2) and the correlation coefficient $\left(r^{2}\right)$ values were $>0.99$ (Table 1$)$.

\section{Stability of Samples}

All three analytes were stable at $-20^{\circ} \mathrm{C}$ storage and the percentage deviation of concentrations from the reference standards was less than $12 \%$ at high, medium, and low concentrations. The gradient of the calibration curve also remained stable over the concentration range investigated, during six weeks, when stored at $-20^{\circ} \mathrm{C}$. The values were compatible with the slope from the freshly made standards suggesting short and long term stability with minimal intraday and interday variability at measured levels over six weeks.

Accuracy was determined by the analysis of recovery. Known amounts of analytes were spiked with water at three concentration levels of each analyte $(12.5,25$, and $75 \mu \mathrm{g} / \mathrm{mL}$ ). The experiment was performed in triplicate and the percentage recovery was determined using the calculated 


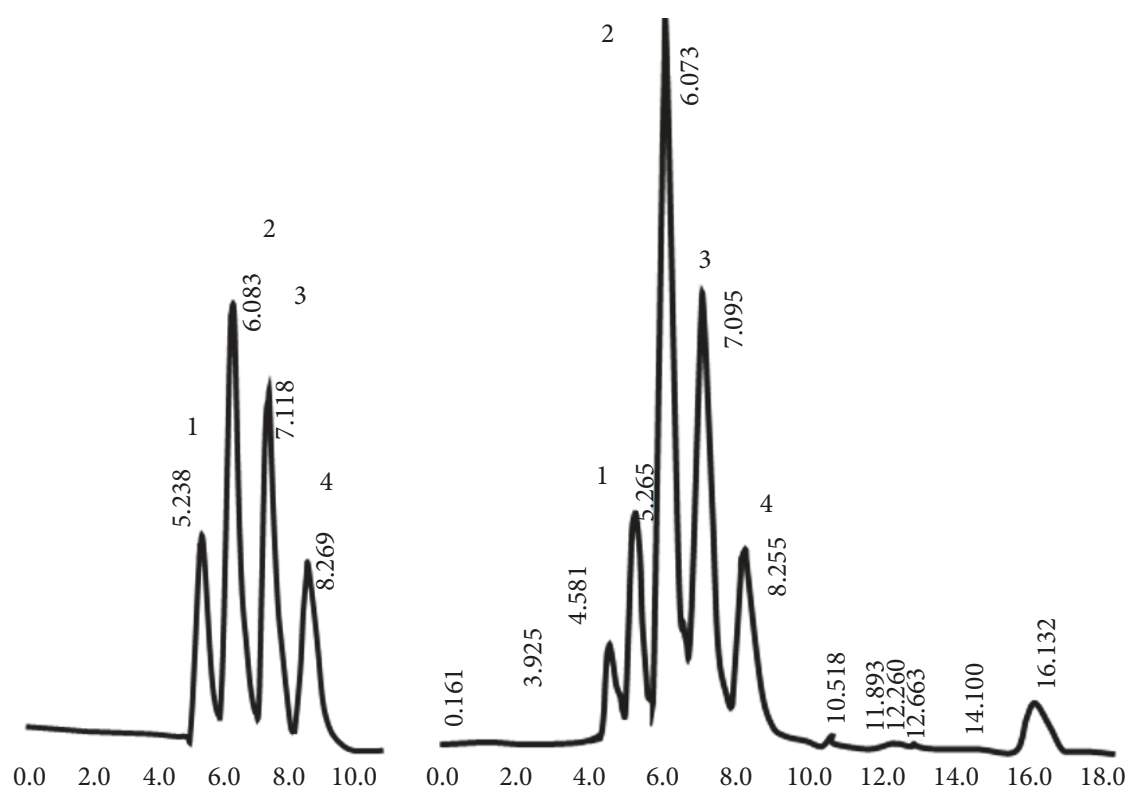

(a)

(b)

FIGURE 1: HPLC chromatograms of (a) standards of uric acid $(75 \mu \mathrm{g} / \mathrm{mL})$, creatinine $(75 \mu \mathrm{g} / \mathrm{mL})$, internal standard, tyrosine $(125 \mu \mathrm{g} / \mathrm{mL})$, and hypoxanthine $(75 \mu \mathrm{g} / \mathrm{mL})$. 1, uric acid (5.2 $\mathrm{min}) ; 2$, creatinine (6.0 min); 3, tyrosine the internal standard (7.1 min); 4, hypoxanthine (8.2 min). (b) HPLC chromatogram of human urine.

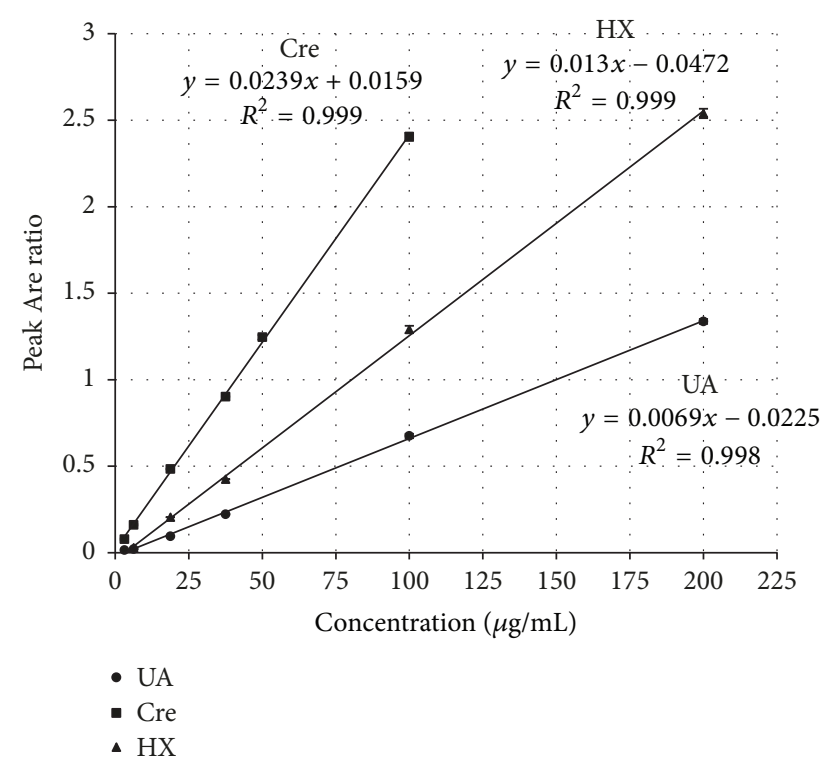

FIgURE 2: Calibration curves obtained for uric acid (UA; 3.12-200 $\mu \mathrm{g} /$ $\mathrm{mL}$ ), creatinine (Cre; $3.12-100 \mu \mathrm{g} / \mathrm{mL}$ ), and hypoxanthine (HX; $6.25-200 \mu \mathrm{g} / \mathrm{mL})(n=5)$.

value, obtained from the calibration curve, to the true value (Table 2).

$$
\% \text { Recovery }=\left(\frac{\text { calculated amount }}{\text { theoretical amount }}\right) \times 100 \%
$$

The recovery for the three analytes at $12.5,25$, and $75 \mu \mathrm{g} / \mathrm{mL}$ was obtained between 97 and 102\% indicating the accuracy of the developed method.

\section{Repeatability}

Coefficient of variation (CV\%) for the repeated injections $(n=3)$ at three quality control levels $(12.5,25$, and $75 \mu \mathrm{g} / \mathrm{mL})$ was analyzed (Table 2$)$. The values $(0.15-0.95 \%)$ were within the accepted range $(15 \%)$ indicating the repeatability of the present validated HPLC/UV method.

\section{Precision}

Intraday $(n=5)$ and interday $(n=8)$ variations were evaluated for precision, by analyzing the quality control samples of the three analytes over six weeks and CV\% were calculated (Table 2).

The CV\% for the three analytes obtained were lower than the recommended value $(15 \%)$ proving the intermediate precision of the developed HPLC/UV method.

\section{Limit of Detection (LOD), Limit of Quantification (LOQ), and Lower Limit of Detection (LLOD)}

LOD, LOQ, and LLOQ are given in the Table 3.

\section{Patient Samples}

Urine samples from six individuals were analyzed (Table 4). 
TABLE 1: Regression equation obtained for interday and intraday variation of uric acid, creatinine, and hypoxanthine.

\begin{tabular}{lccr}
\hline Experiment & Analyte & Regression equation & $r^{2}$ \\
\hline & Uric acid & $Y=0.0069 x-0.022$ & 0.998 \\
Intraday variation $n=5$ & Creatinine & $Y=0.0236 x+0.016$ & 0.999 \\
& Hypoxanthine & $Y=0.0124 x-0.0466$ & 0.999 \\
\hline \multirow{2}{*}{ Interday variation $n=8$} & Uric acid & $Y=0.006 x-0.008$ & 0.995 \\
& Creatinine & $Y=0.0218 x+0.028$ & 0.998 \\
& Hypoxanthine & $Y=0.0124 x-0.006$ & 0.997 \\
\hline
\end{tabular}

$Y$, peak area ratio (peak area of the analyte to that of the internal standard); $x$, concentration of the analyte; $r^{2}$, correlation coefficient.

TABLE 2: Accuracy, repeatability, and precision for uric acid, creatinine, and hypoxanthine.

\begin{tabular}{|c|c|c|c|c|}
\hline & \multirow{2}{*}{ Accuracy $($ recovery $\%) n=5$} & \multirow{2}{*}{ Repeatability CV\% } & \multicolumn{2}{|c|}{ Precision (CV\%) } \\
\hline & & & Intraday $(n=5)$ & Interday $(n=8)$ \\
\hline \multicolumn{5}{|c|}{ Uric acid $(\mu \mathrm{g} / \mathrm{mL})$} \\
\hline 12.5 & $98.17 \pm 0.57$ & 0.35 & 0.74 & 4.62 \\
\hline 25 & $100.12 \pm 0.16$ & 0.50 & 1.20 & 3.84 \\
\hline 75 & $99.49 \pm 0.13$ & 0.15 & 0.53 & 1.64 \\
\hline \multicolumn{5}{|c|}{ Creatinine $(\mu \mathrm{g} / \mathrm{mL})$} \\
\hline 12.5 & $97.52 \pm 0.38$ & 0.95 & 1.88 & 4.40 \\
\hline 25 & $101.44 \pm 0.21$ & 0.56 & 0.59 & 4.58 \\
\hline 75 & $99.84 \pm 0.42$ & 0.81 & 0.73 & 1.41 \\
\hline \multicolumn{5}{|c|}{ Hypoxanthine $(\mu \mathrm{g} / \mathrm{mL})$} \\
\hline 12.5 & $100.32 \pm 1.75$ & 0.35 & 0.31 & 3.53 \\
\hline 25 & $100.43 \pm 1.02$ & 0.63 & 0.37 & 3.13 \\
\hline 75 & $100.40 \pm 0.15$ & 0.19 & 1.64 & 1.40 \\
\hline
\end{tabular}

CV\%, coefficient of variation; $n$, number of replications of analyte samples.

TABLE 3: Limit of quantification (LOQ), limit of detection (LOD), and lower limit of quantification (LLOQ) for uric acid, creatinine, and hypoxanthine.

\begin{tabular}{lccc}
\hline Analyte & LOQ $(\mu \mathrm{g} / \mathrm{mL})$ & LOD $(\mu \mathrm{g} / \mathrm{mL})$ & LLOQ $(\mu \mathrm{g} / \mathrm{mL})$ \\
\hline Uric acid & 0.89 & 0.30 & 3.12 \\
Creatinine & 1.05 & 0.35 & 3.12 \\
Hypoxanthine & 0.84 & 0.28 & 6.25 \\
\hline
\end{tabular}

TABLE 4: Concentrations of uric acid (UA), hypoxanthine (HX), and creatinine (Cre) and the ratios for purine metabolite to creatinine in urine samples of six individuals.

\begin{tabular}{lcccc}
\hline Cre $(\mu \mathrm{g} / \mathrm{mL})$ & $\mathrm{UA}(\mu \mathrm{g} / \mathrm{mL})$ & $\mathrm{HX}(\mu \mathrm{g} / \mathrm{mL})$ & $\mathrm{UA} /$ Cre & HX/Cre \\
\hline 1425.54 & 739.43 & 364.13 & 0.52 & 0.25 \\
850.30 & 675.38 & 114.34 & 0.79 & 0.13 \\
621.95 & 383.14 & 61.31 & 0.62 & 0.10 \\
1056.72 & 918.89 & 93.95 & 0.87 & 0.09 \\
1082.33 & 1123.41 & 347.63 & 1.04 & 0.32 \\
1116.87 & 1737.85 & 373.85 & 1.56 & 0.33 \\
\hline
\end{tabular}

\section{Conclusion}

The present study describes a simple, less expensive isocratic method for the simultaneous analysis of uric acid, creatinine, and hypoxanthine. The method can be employed for the analysis of purine metabolism defects using human urine samples with normalization with creatinine.

\section{Data Availability}

The data [HPLC chromatogram, graphics, and tables] used to support the findings of this study are included within the article. All the necessary data are included in the manuscript and data sharing is not applicable to this paper.

\section{Ethical Approval}

Ethical approval was obtained from Ethics Review Committee, Faculty of Medicine, University of Colombo, Sri Lanka.

\section{Conflicts of Interest}

The authors declare that there are no conflicts of interest regarding the publication of this paper.

\section{Authors' Contributions}

Nimanthi Wijemanne performed all the laboratory experiments, analyzed data, and wrote the draft. Preethi Soysa designed and analyzed data, supervised the study, and rewrote the final manuscript. Sulochana Wijesundara and 
Hemamali Perera proposed the research idea and edited the manuscript.

\section{Acknowledgments}

This work was supported by Funds available in the Department of Biochemistry and Molecular Biology, University of Colombo, Sri Lanka, which are greatly acknowledged.

\section{References}

[1] H. A. Jinnah, R. L. Sabina, and G. Van Den Berghe, "Metabolic disorders of purine metabolism affecting the nervous system," Handbook of Clinical Neurology, vol. 113, pp. 1827-1836, 2013.

[2] J. Maiuolo, F. Oppedisano, S. Gratteri, C. Muscoli, and V. Mollace, "Regulation of uric acid metabolism and excretion," International Journal of Cardiology, vol. 213, pp. 8-14, 2016.

[3] D. Gustafsson and R. Unwin, "The pathophysiology of hyperuricaemia and its possible relationship to cardiovascular disease, morbidity and mortality," BMC Nephrology, vol. 14, no. 1, article 164, 2013.

[4] M. Kuwabara, "Hyperuricemia, Cardiovascular Disease, and Hypertension," Pulse, vol. 3, no. 3-4, pp. 242-252, 2016.

[5] F.-Y. Chu, C.-C. Chang, P.-H. Huang et al., "The Association of Uric Acid Calculi with Obesity, Prediabetes, Type 2 Diabetes Mellitus, and Hypertension," BioMed Research International, vol. 2017, Article ID 7523960, 2017.

[6] C. Zhu, R. Cui, M. Gao et al., "The Associations of Serum Uric Acid with Obesity-Related Acanthosis nigricans and Related Metabolic Indices," International Journal of Endocrinology, vol. 2017, Article ID 5438157, 2017.

[7] Y. Zuo, Y. Yang, Z. Zhu, W. He, and Z. Aydin, "Hydrophilic interaction chromatographic determination of uric acid, a biomarker for hyperuricemia and antioxidant capacity, and creatinine in human urine," Talanta, vol. 82, pp. 1707-1710, 2011.

[8] S. Zhou, R. Zuo, Z. Zhu et al., "An eco-friendly hydrophilic interaction HPLC method for the determination of renal function biomarkers, creatinine and uric acid, in human fluids," Analytical Methods, vol. 5, no. 5, pp. 1307-1311, 2013.

[9] K. Kalantari and W. Kline Bolton, "A good reason to measure 24-hour urine creatinine excretion, but not to assess kidney function," Clinical Journal of the American Society of Nephrology, vol. 8, no. 11, pp. 1847-1849, 2013.

[10] M. A. Pearson, C. Lu, B. J. Schmotzer, L. A. Waller, and A. M. Riederer, "Evaluation of physiological measures for correcting variation in urinary output: Implications for assessing environmental chemical exposure in children," Journal of Exposure Science and Environmental Epidemiology, vol. 19, no. 3, pp. 336342, 2009.

[11] A. H. Garde, Å. M. Hansen, J. Kristiansen, and L. E. Knudsen, "Comparison of Uncertainties Related to Standardization of Urine Samples with Volume and Creatinine Concentration," Annals of Occupational Hygiene, vol. 48, no. 2, pp. 171-179, 2004.

[12] M. F. Boeniger, L. K. Lowry, and J. Rosenberg, "Interpretation of urine results used to assess chemical exposure with emphasis on creatinine adjustments: a review," American Industrial Hygiene Association Journal, vol. 54, no. 10, pp. 615-627, 1993.

[13] L. Xiang, J. Li, J. Lin, and H. Li, "Determination of gouty arthritis' biomarkers in human urine using reversed-phase high-performance liquid chromatography," Journal of Pharmaceutical Analysis, vol. 4, no. 2, pp. 153-158, 2014.
[14] K. J. Shingfield and N. W. Offer, "Simultaneous determination of purine metabolites, creatinine and pseudouridine in ruminant urine by reversed-phase high-performance liquid chromatography," Journal of Chromatography B: Biomedical Sciences and Applications, vol. 723, no. 1-2, pp. 81-94, 1999.

[15] P. G. del Moral, M. T. Di, J. A. Resines, I. G. Bravo, and M. J. Ari, "Simultaneous Measurements of Creatinine and Purine Derivatives in Ruminants Urine Using Ion-Pair HPLC," Journal of Liquid Chromatography Related Technologies, vol. 26, no. 17, pp. 2961-2968, 2003.

[16] M. Czauderna and J. Kowalczyk, "Quantification of allantoin, uric acid, xanthine and hypoxanthine in ovine urine by highperformance liquid chromatography and photodiode array detection," Journal of Chromatography B: Biomedical Sciences and Applications, vol. 744, no. 1, pp. 129-138, 2000.

[17] T. Seki, Y. Orita, K. Yamaji, and A. Shinoda, "Simultaneous determination of creatinine, hypoxanthine and uric acid in biological samples by column-switching liquid chromatography with ultraviolet detection," Journal of Pharmaceutical and Biomedical Analysis, vol. 15, no. 9-10, pp. 1621-1626, 1997.

[18] M. K. N. W. Ekanayake and S. S. S. B. D. P. Soysa, “Development and Validation of High Performance Liquid Chromatography/ UV Method for Simultaneous Determination of Urinary Uric Acid, Hypoxanthine and Creatinine," in Pittcon Conference and Expo 2011 Atlanta, USA, 2011.

[19] J. K. Taylor, Quality Assurance of Chemical, Measurements, Lewis Publisher, Chelsea, Michign, USA, 1987.

[20] Y. Zuo, C. Wang, J. Zhou, A. Sachdeva, and V. C. Ruelos, "Simultaneous Determination of Creatinine and Uric Acid in Human Urine by High-Performance Liquid Chromatography," Analytical Sciences, vol. 24, no. 12, pp. 1589-1592, 2008. 

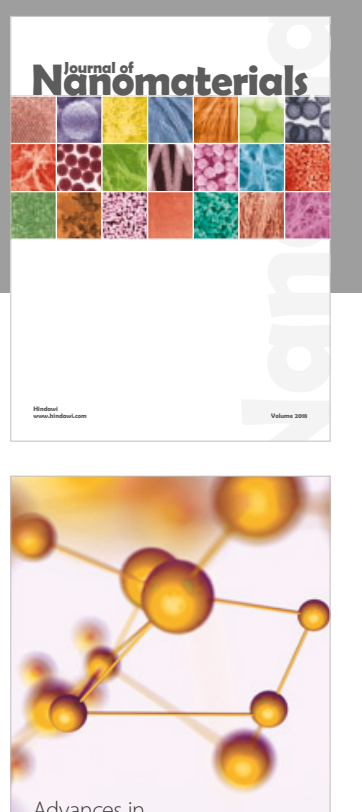

Physical Chemistry
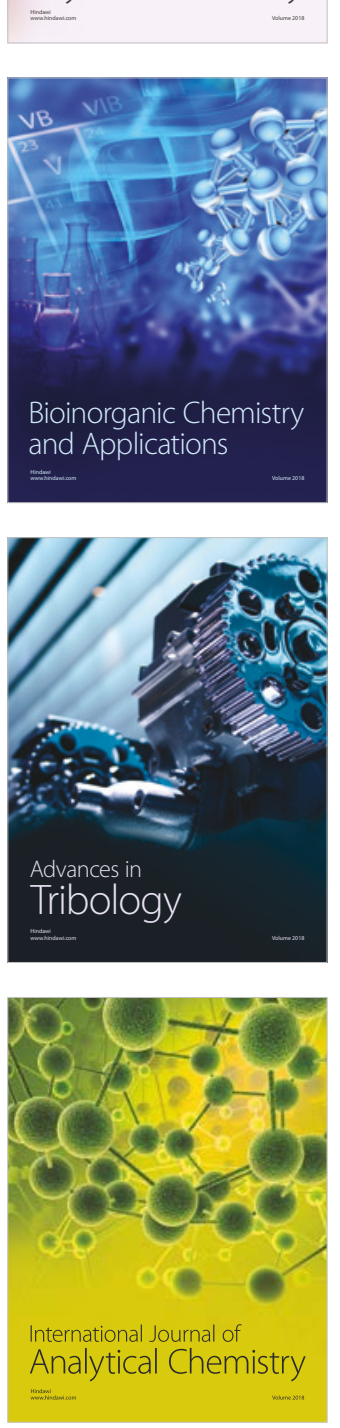

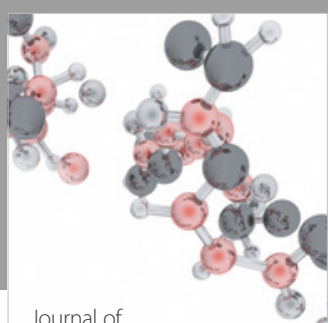

Analytical Methods

in Chemistry

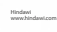

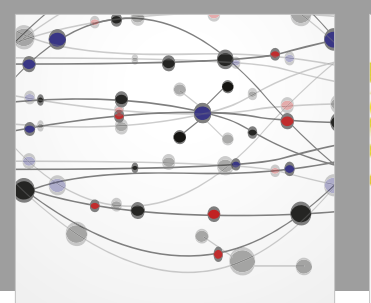

The Scientific World Journal

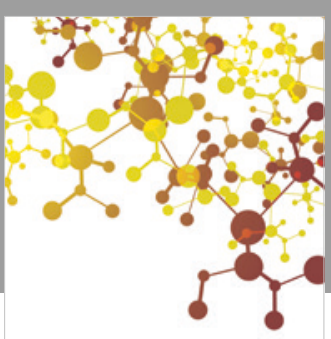

Journal of

Applied Chemistry
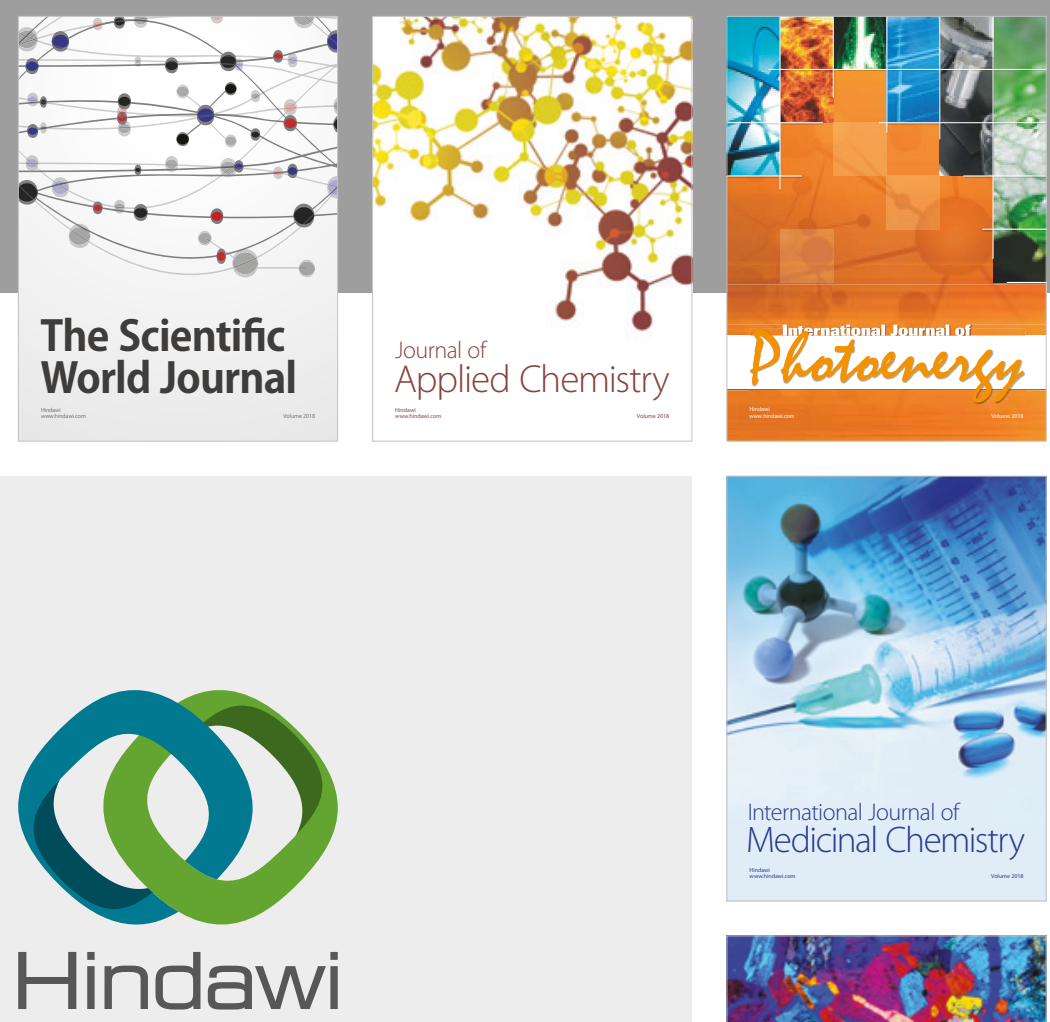

Submit your manuscripts at

www.hindawi.com
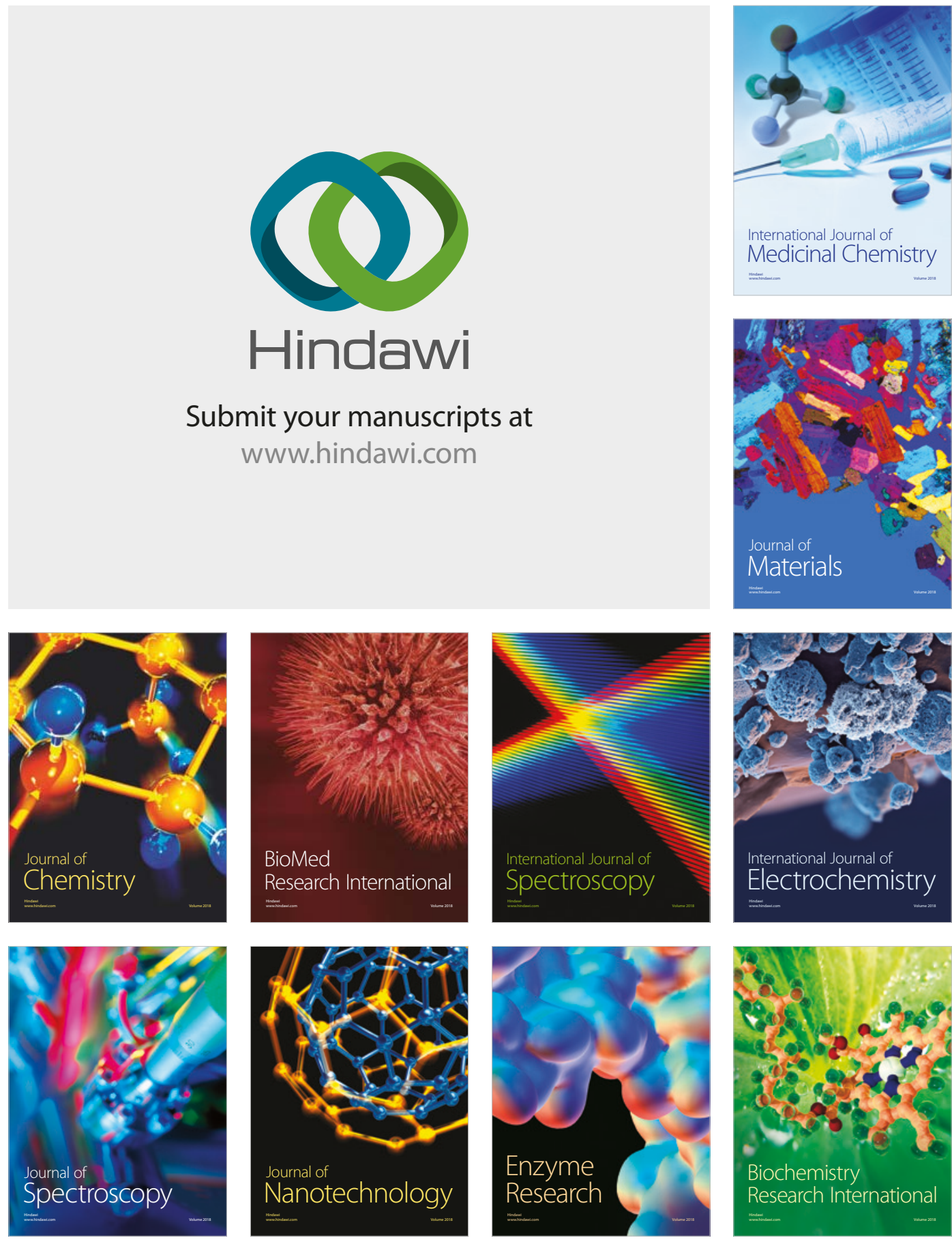
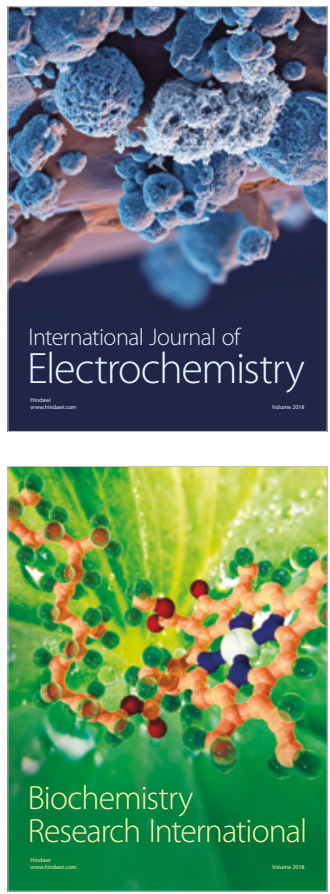